\title{
Basic Characteristics of Hemimorphite and Its Transformation Mechanism with $\mathrm{Na}_{2} \mathrm{CO}_{3}$
}

\author{
Qihong Wang ${ }^{1,2}$, Xiaolin Zhang ${ }^{1,2, *}$, Dianwen Liu ${ }^{1,2, *}$, Shiming Cao ${ }^{3}$ (D), Kaiwei Song ${ }^{1,2}$, \\ Man Jing ${ }^{2}$, Kangkang $\mathrm{Li}^{2}$, Luqing $\mathrm{Wu}^{2}$ and Ruizeng $\mathrm{Liu}^{1,2}$ \\ 1 State Key Laboratory of Complex Nonferrous Meal Resources Clean Utilization, Kunming University \\ of Science and Technology, Kunming 650093, China; wang_qi_hong@126.com (Q.W.); \\ kivy340827@126.com (K.S.); liuruizeng@126.com (R.L.) \\ 2 Faculty of Land Resource Engineering, Kunming University of Science and Technology, \\ Kunming 650000, China; xkdjingman@163.com (M.J.); kkl163163@163.com (K.L.); \\ aa1321615400@163.com (L.W.) \\ 3 School of Chemical Engineering \& Technology, China University of Mining and Technology, \\ Xuzhou 221000, China; ironshark@163.com \\ * Correspondence: xiaolin6001@sina.com (X.Z.); dianwenliu@kmust.edu.cn (D.L.)
}

Received: 16 January 2018; Accepted: 29 March 2018; Published: 3 April 2018

\begin{abstract}
The crystal of hemimorphite is a non-conductor. The $\mathrm{Si}-\mathrm{O}$ bond in the crystal is strong, whereas the $\mathrm{Zn}-\mathrm{O}$ bond is weak. These properties lead to the easy breakage of the $\mathrm{Zn}-\mathrm{O}$ bond in the crushing process of hemimorphite. Thus, the interaction between minerals and polar water molecules is strong, and natural floatability of ores is poor. This study systematically investigated the characteristics of hemimorphite and its action mechanism with $\mathrm{Na}_{2} \mathrm{CO}_{3}$. Results of SEM-EDS showed that the surface of hemimorphite dissolved after interacting with $\mathrm{Na}_{2} \mathrm{CO}_{3}$, and the contents of $\mathrm{Si}$ and $\mathrm{O}$ decreased, whereas $\mathrm{Zn}$ and $\mathrm{C}$ increased. XPS analysis showed that the carbonate group was detected. The interaction between $\mathrm{CO}_{3}{ }^{2-}$ and hemimorphite was calculated using the first principles calculation based on density functional theory. The results indicate that an $\mathrm{O}$ atom in $\mathrm{CO}_{3}{ }^{2-}$ interacted with $\mathrm{Zn}^{2+}$ from the (100) plane of hemimorphite. The interaction between $\mathrm{Zn}$ and $\mathrm{O}$ atoms was not strong, and the $\mathrm{Zn}$ atoms were not completely displaced, which was proven by density of state analysis and the EDS and XPS results. The Mulliken population showed that the $\mathrm{O}-\mathrm{Zn}$ bond was the atomic bonding of $\mathrm{CO}_{3}{ }^{2-}$ with $\mathrm{Zn}^{2+}$ and exhibited properties of ionic bonds. Thus, hemimorphite transformed to smithsonite-like mineral $\left(\mathrm{ZnCO}_{3}\right)$ when acting with $\mathrm{CO}_{3}{ }^{2-}$.
\end{abstract}

Keywords: sodium carbonate $\left(\mathrm{Na}_{2} \mathrm{CO}_{3}\right)$; hemimorphite; transformation mechanism; smithsonite-like mineral

\section{Introduction}

Zinc oxide ore is an important zinc mineral resource that is accompanied with technical problems during actual separation because of its various mineral resources, inlay complexity, and high soluble salt content [1,2]. Minerals are easily slimed and lead to heavy metal loss. Mineral surfaces contaminated with other minerals are not easy to mineralize into monomers [3]. In the application of zinc oxide ore flotation reagents, Dong et al. [4] from Hunan Research Institute of nonferrous metals used advanced xanthate and chelating collectors for the beneficiation of complex zinc oxide ore, and a good concentrate index was obtained. Zhou et al. [5] used sodium fluorosilicate and sodium silicate as inhibitors of gangue minerals which effectively promoted the recovery of zinc oxide ore. The recovery of oxidized zinc ores is usually carried out by flotation when fatty amines are used as collectors. This techniques characterized by the consumption of large amounts of reagents, and careful optimization of reagent proportion is needed [6]. 
To study hemimorphite activation, some researchers [7] conducted calculations of radical electronegativity and ultraviolet band spectrochemical analysis and used a series of analytical methods. They found that $\mathrm{N}$ and $\mathrm{O}$ atoms in $\alpha$-nitroso- $\beta$-naphthol generate a corresponding chelate, which is a compound with $\mathrm{Zn}^{2+}$, on mineral surfaces upon the occurrence of bonding interactions. When $\alpha$-nitroso- $\beta$-naphthol is used as an activating agent, the hydrophobicity of minerals is enhanced. Chen et al. [8] of Guangxi University found that $\mathrm{OH}^{-}$and $\mathrm{HS}^{-}$both exert an activation effect on hemimorphite. An obvious synergistic effect was observed in the $\mathrm{pH}$ range of 9-11. The " $\mathrm{Na}_{2} \mathrm{~S}-\mathrm{Pb}$ (II)-xanthate" process can be successfully used for the flotation of hemimorphite, increasing the recovery rate from $40 \%$ to $90 \%$. PbS is generated when an ion exchange mechanism occurs between $\mathrm{Pb}(\mathrm{II})$ and $\mathrm{ZnS}$, as proven by X-ray diffraction results [9]. Similar effects of $\mathrm{Pb}(\mathrm{II})$ on hemimorphite were also observed in the sodium oleate flotation system [10]. Besides, mechanical activation significantly influences the physicochemical properties of hemimorphite, such as morphologies, crystal structures, and particle size distributions [11].

The present study aimed to investigate the characteristics of hemimorphite and its transformation mechanism with $\mathrm{Na}_{2} \mathrm{CO}_{3}$. SEM-EDS and XPS were conducted to analyze the surface morphology, elemental changes and chemical states in minerals. We used computer simulation techniques to model the transformation of $\mathrm{CO}_{3}{ }^{2-}$ on hemimorphite. The results can provide important insight into the transformation mechanism of $\mathrm{CO}_{3}{ }^{2-}$ on hemimorphite.

\section{Experimental}

\subsection{Materials and Reagents}

The hemimorphite sample used in these experiments was collected from Lanping in Yunnan Province, China. For transform experiments, the hemimorphite sample was crushed and dry ground in an agate mortar. Ground products were sieved to achieve a particle fraction of $-74 \mu \mathrm{m}$ accounts for $85 \%$. Multi-elements analysis showed that the sample contained $53.81 \% \mathrm{Zn}$, which indicated high purity except for low levels of mineral impurities. X-ray diffraction (XRD) (Shimadzu, Kyoto, Japan) pattern of samples shown in Figure 1, hemimorphite crystal was observed, and the diffraction peak is consistent with the data presented in the JCPDS card. Analytical-grade $\mathrm{Na}_{2} \mathrm{CO}_{3}$ and $\mathrm{NaOH} / \mathrm{H}_{2} \mathrm{SO}_{4}$ were employed as activator and regulator, respectively. Pure deionized water with a resistivity of $18 \mathrm{M} \Omega$ obtained from a Milli-Q5O system (Billerica, MA, USA) was used in these experiments.

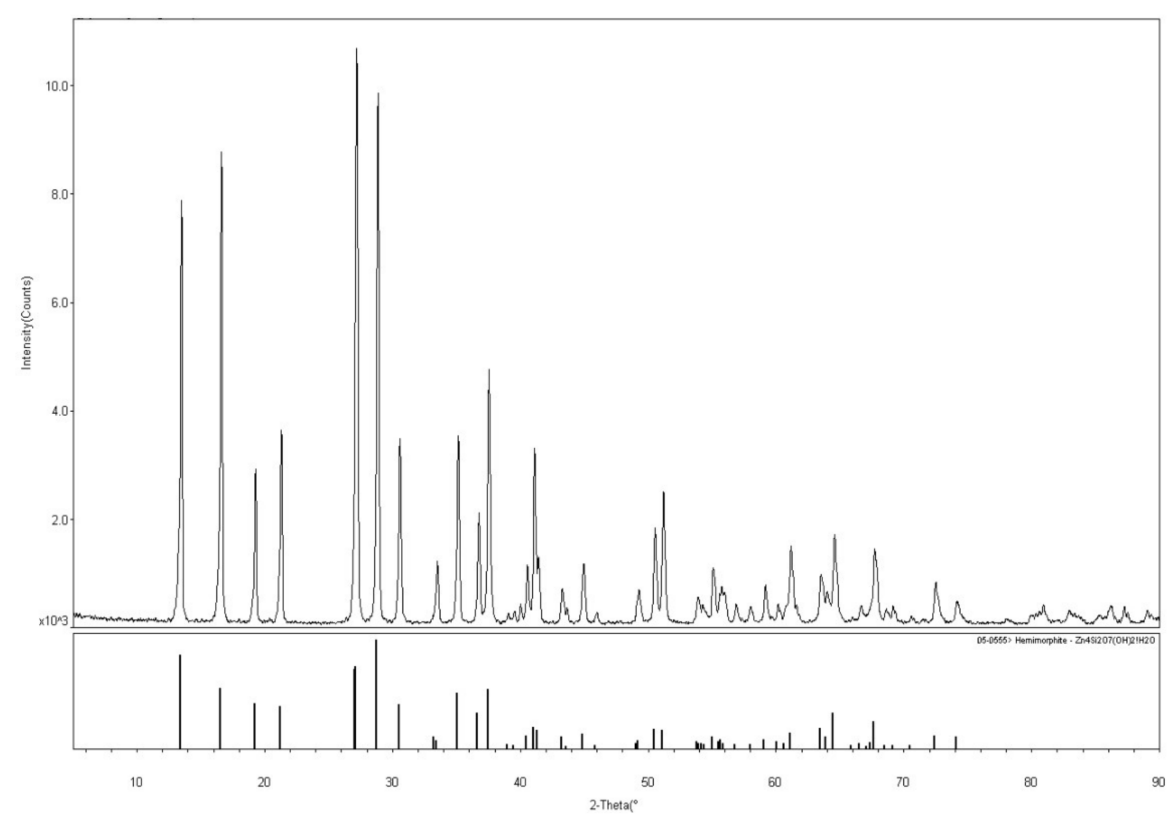

Figure 1. X-ray diffraction (XRD) pattern of the pure hemimorphite samples. 


\subsection{SEM-EDS Analysis}

Before and after acting with $\mathrm{Na}_{2} \mathrm{CO}_{3}$, the surface morphology and composition of the hemimorphite were examined by SEM-EDS under the Jeol JSM-6360 instrument (JEOL, Tokyo, Japan) at $20 \mathrm{kV}$.

\subsection{XPS Analysis}

The XPS measurements were performed using PHI5000 Versa Probe II (ULVAC-PHI, Chigasaki-shi,

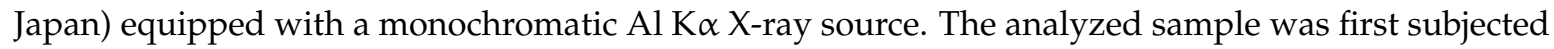
to a survey scan to identify chemical components, followed by high-resolution scans on a certain element. Carbon is ubiquitous and is present on all surfaces for XPS analysis. Thus, all spectra were calibrated using the carbon 1s spectral peak at $284.8 \mathrm{eV}$.

\subsection{Computational Methods}

Calculations in this article were conducted using Cambridge Serial Total Energy Package developed by Payneet al. [12]. This software package is the first-principle method based on density functional theory (DFT). Hemimorphite is a nesosilicate mineral and an orthorhombic system [13,14]. It contains a 3D spatial skeleton formed by a connected vertex between $\mathrm{Si}-\mathrm{O}$ double tetrahedra and $\mathrm{Zn}-\mathrm{O}$ tetrahedra in its crystal structure. The three corners of the tetrahedron are bonded together and form a six-atomic ring $(2 \mathrm{Zn}+\mathrm{Si}+3 \mathrm{O})$, which is connected with each other on the (010) surface to form an unlimited extension of the layer. The electronic structure of the ore was calculated via DFT $[15,16]$, and the optimized crystal cell model is shown in Figure 2.

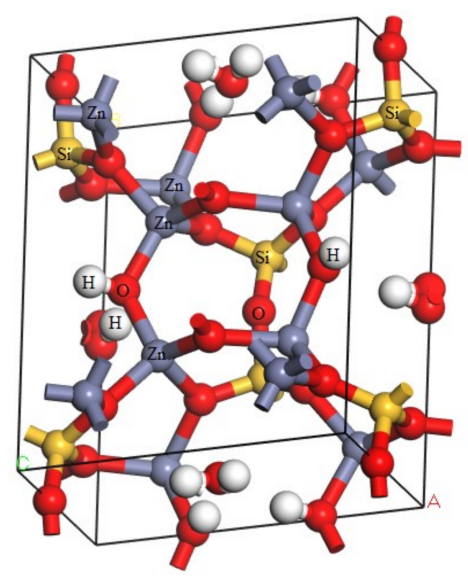

Figure 2. Cell model of hemimorphite.

\section{Results and Discussion}

\subsection{Analysis of Energy Band Structure and Density of States of Hemimorphite}

Energy band theory $[17,18]$ can be used to qualitatively explain the motion characteristics of electrons in the crystal structure. The energy band structure of hemimorphite (Figure 3) mainly consists of three parts, conduction band $(3.3 \mathrm{eV}$ to $11.5 \mathrm{eV})$, valence band $(-17.4 \mathrm{eV}$ to $-16.5 \mathrm{eV})$, and filled band $(-8.5 \mathrm{eV}$ to $0.68 \mathrm{eV})$. The conduction band is conductive, whereas the position in the filled band is full of electrons and does not show electrical conductivity. The valence band is occupied by the valence electron. The electronic movement as a whole is symmetrical when produced by the external force, and neither has electrical property. By contrast, electrical properties are exhibited when the motion of the electron is asymmetric. The energy band gap was analyzed, which demonstrated that the energy band gap of hemimorphite was $3.336 \mathrm{eV}$, differing greatly from another zinc oxide ore [19], but it was close to that of smithsonite $(3.529 \mathrm{eV})$ [20]. These properties indicate the weak 
electron mobility and poor conductivity of hemimorphite. Figure 4 presents the density of states of hemimorphite. The energy band was divided into four parts in the range of $-19.7 \mathrm{eV}$ to $11.0 \mathrm{eV}$. The valence band from $-17.4 \mathrm{eV}$ to $16.5 \mathrm{eV}$ was mainly composed of the s orbitals and p orbitals, which also contributed to the density of states of hemimorphite. The valence band, which ranged from $-8.5 \mathrm{eV}$ to $-7.1 \mathrm{eV}$, was mainly made up of $\mathrm{p}$ orbitals and s orbitals, and most of them were $\mathrm{p}$ orbitals. The valence band mainly consisted of $\mathrm{d}$ and $\mathrm{p}$ orbitals in the range of $-7.1 \mathrm{eV}$ to $0.68 \mathrm{eV}$, and the s orbitals contributed as well. In addition, the conduction band energy level was mainly composed of $\mathrm{p}$ and s orbitals, and the contributions of the two orbitals did not considerably differ. The density of states near the Fermi level was made up primarily of $\mathrm{p}$ and d orbitals, which indicated that this crystal was a non-conductor. These results were consistent with the findings of energy band analysis.

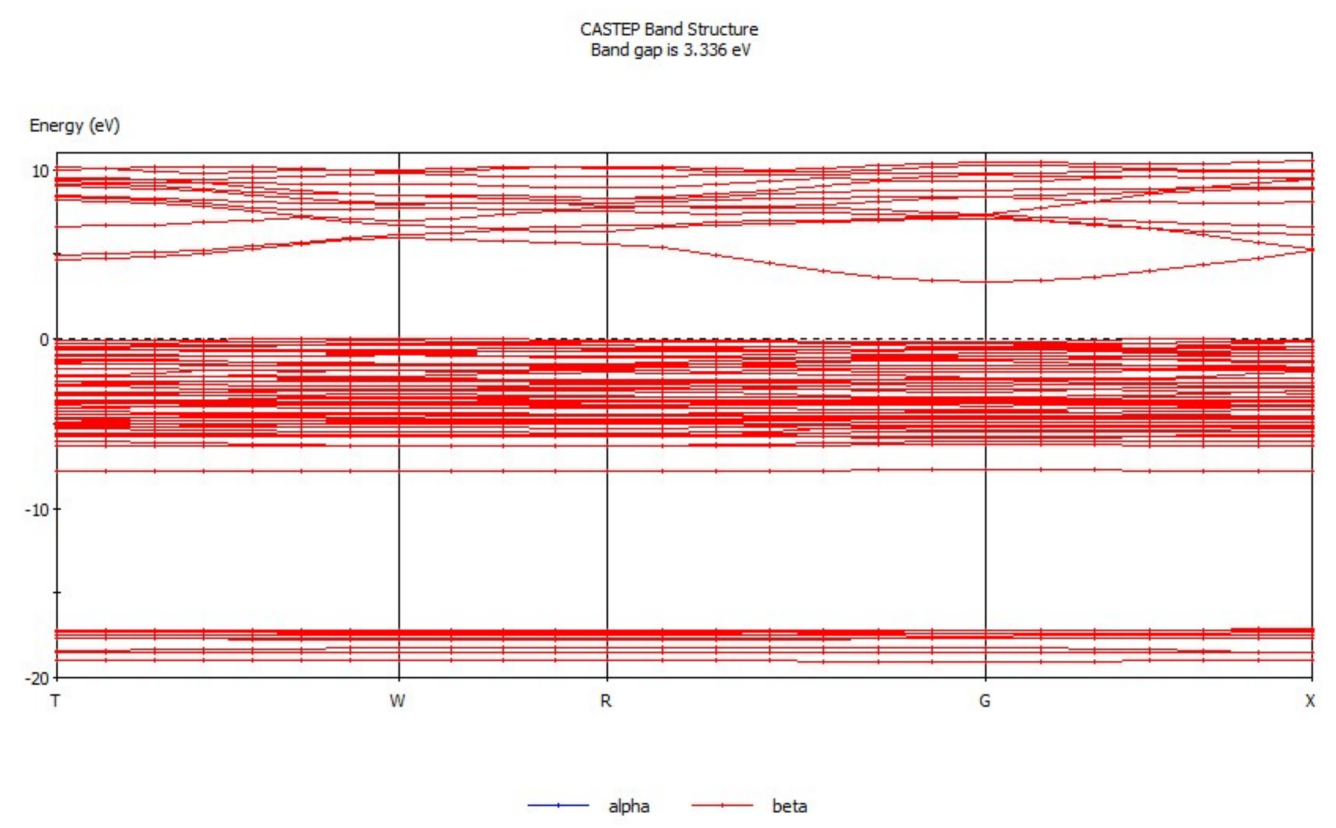

Figure 3. Energy band diagram of hemimorphite.

CASTEP Partial Density of States

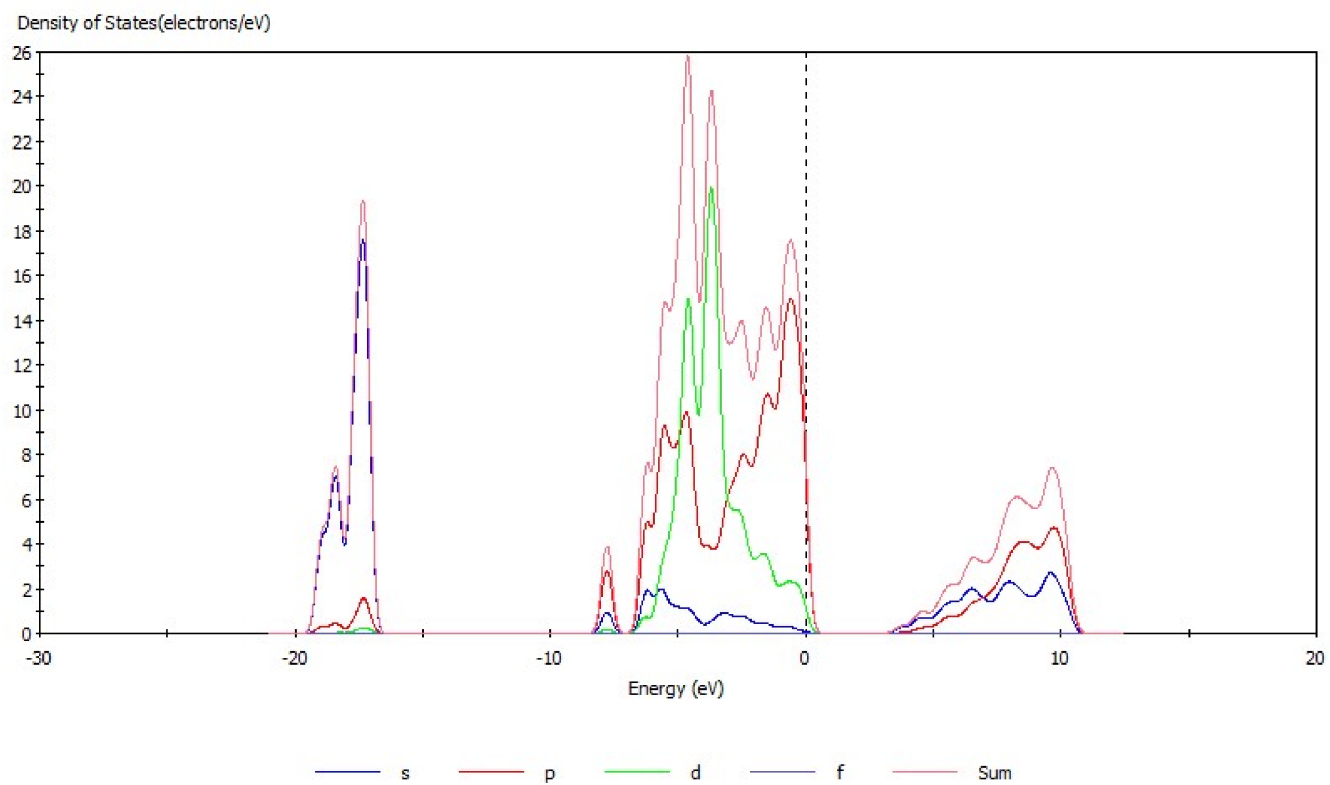

Figure 4. Partial densities of states of hemimorphite. 


\subsection{Mulliken Population Analysis}

Mulliken population is a method used to describe the distribution of electric charge between the correlated atoms, and it can demonstrate the charge distribution, transfer, bonding, and other information in a simulated system [21-24]. Professor $\mathrm{Hu}$ [25] proposed that bond energy $\mathrm{E}_{\mathrm{AB}}$ considers the population of overlapping atomic orbitals and different contributions caused by varying levels in the molecular orbital. The present study only analyzed the influence of the Mulliken population on bond energy intensity. The Mulliken population was successfully applied to the $\mathrm{S}_{\mathrm{N}} 2$ reaction with resonance theory by Ikeda et al. [26]. When the Mulliken population of bonds is large, the covalent bond between atoms is strong; if it is small, there is minimal overlap of electronic clouds and bond covalency is weak. The bond between atoms is ionic when the Mulliken population is low [27-29]. The Mulliken population of hemimorphite is presented in Table 1, which shows that the bond length of Si-O was $1.6153 \AA$ (average value). The population was 0.5975 (average value), and its covalency was strong. The bond length of $\mathrm{Zn}-\mathrm{O}$ was $1.9529 \AA$ (average value), and the population was 0.36 (average value). Therefore, ionicity for its covalency was weaker than that of the Si-O bond. Kaupp et al. [30] also reported further details in his research on bond length/bond strength.

Table 1. Mulliken population value of partial bonds of hemimorphite.

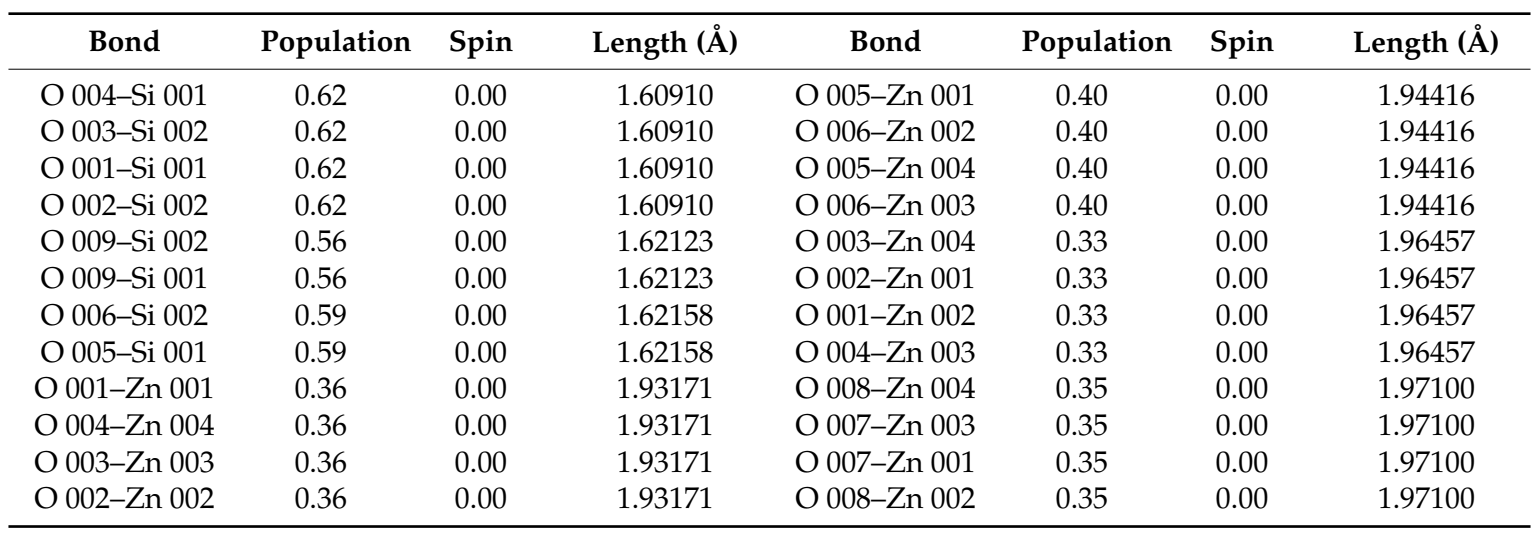

\subsection{Charge Density Difference of Hemimorphite}

The analysis of the charge density difference of atoms revealed information on atomic bonding and gain and loss of electrons [31]. As shown in the charge density difference map of hemimorphite in Figure 5, the blue region represents electron deficiency, the red area represents the electron concentration, and the white area shows minimal changes in electron density. The charge density difference of the $\mathrm{Si}-\mathrm{O}$ bond is illustrated on the left side of Figure 4, whereas the right part illustrates the charge density difference of the $\mathrm{Zn}-\mathrm{O}$ bond. The $\mathrm{Si}-\mathrm{O}$ bond was covalent due to the large overlap of electron cloud between $\mathrm{Si}-\mathrm{O}$ atoms in the internal structure of the crystal of hemimorphite. By contrast, the $\mathrm{Zn}-\mathrm{O}$ bond showed iconicity because its degree of overlap was small with a low inter-atomic force. The floatability of minerals can be greatly influenced by their surface bond energy [32]. Minerals with weak covalency and strong iconicity demonstrate strong hydrophilicity but good floatability. Given that the $\mathrm{Si}-\mathrm{O}$ bond in hemimorphite was very strong, the $\mathrm{Zn}-\mathrm{O}$ bond was often broken during crushing and grinding, resulting in the high presence of the $\mathrm{Zn}-\mathrm{O}$ bond on the exposed mineral surface. The $\mathrm{Zn}-\mathrm{O}$ bond exhibited strong ionicity and weak covalency, so minerals often showed a strong force with polar water molecules; this phenomenon was the reason for the poor flotability of hemimorphite. Ore is easily slimed during crushing and separating if the proportion of $\mathrm{Si}$ in the mineral composition is high, leading to minerals being hard to separate effectively $[33,34]$. Thus, high-silicon hemimorphite was also difficult to separate. 


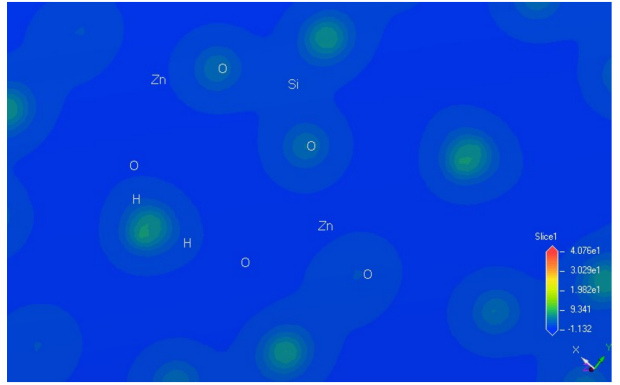

(a)

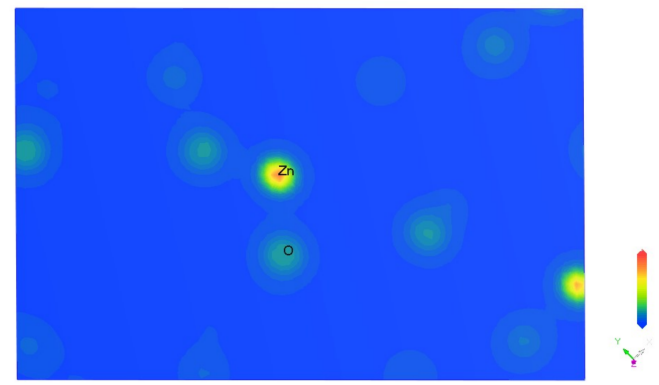

(b)

Figure 5. Charge density difference map of hemimorphite. (a) Si-O bond; (b) Zn-O bond.

\subsection{Transformation Mechanism of $\mathrm{CO}_{3}{ }^{2-}$ on Hemimorphite}

The hemimorphite surface was analyzed by SEM-EDS before and after treatment with $\mathrm{Na}_{2} \mathrm{CO}_{3}$ (Figure 6). Cao's research has proved that the floatability of hemimorphite behaves well when $\mathrm{pH}=10.0$ [35]. Thus, transform experiment was carried out when $\mathrm{Na}_{2} \mathrm{CO}_{3}\left(1 \times 10^{-3} \mathrm{~mol} / \mathrm{L}\right)$ as activator, and the pulp $\mathrm{pH}$ was adjusted to $\mathrm{pH}=10.0$ by $\mathrm{NaOH} / \mathrm{H}_{2} \mathrm{SO}_{4}$ with 3 minutes treatment. Before the reaction, the dissociation surface of pure minerals was relatively flat with a pebble-like texture; the mineral surface turned concave and convex and exhibited breccias after the reaction. Thus, $\mathrm{Na}_{2} \mathrm{CO}_{3}$ exerted significant dissolution to the surface of hemimorphite. EDS analysis revealed that the contents of $\mathrm{O}$ and $\mathrm{Si}$ on the surface of hemimorphite decreased, whereas $\mathrm{Zn}$ and $\mathrm{C}$ increased after the reaction with $\mathrm{Na}_{2} \mathrm{CO}_{3}$. Elemental $\mathrm{Si}$ and $\mathrm{O}$ in hemimorphite mainly existed in the form of $\mathrm{Si}_{2} \mathrm{O}_{7}{ }^{6-}$, so the decrease in the contents of $\mathrm{O}$ and $\mathrm{Si}$ was caused by the micro dissolution of $\mathrm{Si}_{2} \mathrm{O}_{7}{ }^{6-}$ in solution. Simultaneously, the dissolution of $\mathrm{Si}_{2} \mathrm{O}_{7}{ }^{6-}$ led to the increase in bare $\mathrm{Zn}^{2+}$ on the surface of hemimorphite, which increased the $\mathrm{Zn}$ content. Furthermore, the significant increase in the $\mathrm{C}$ content was mainly due to the combination with bare $\mathrm{Zn}^{2+}$ and then transformed smithsonite-like minerals that were not identical. As seen in the Table 2, the carbon content increased from $0.60 \%$ to $3.61 \%$ after acting, however, is still at a low level.
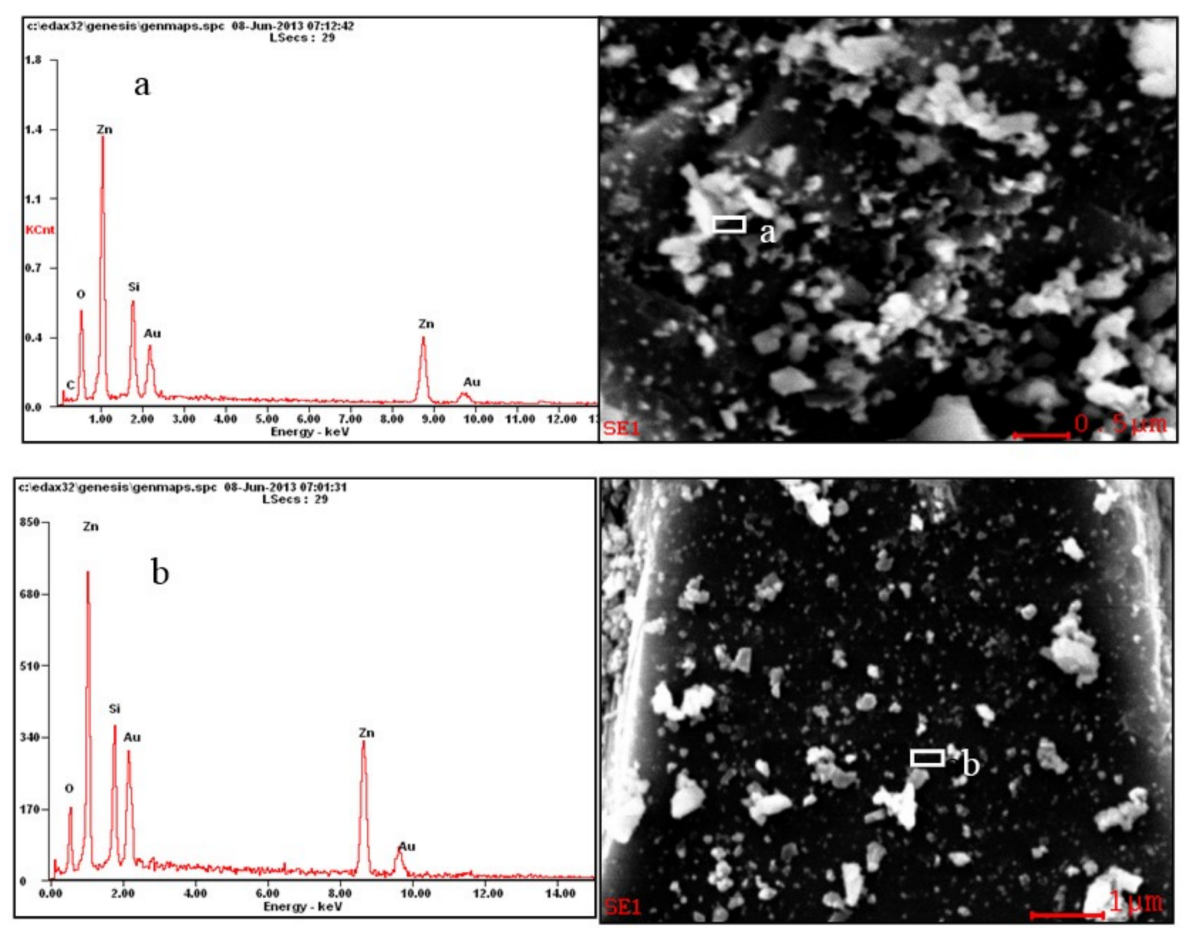

Figure 6. Energy dispersive spectroscopy of hemimorphite before $(\mathbf{a})$ and after $(\mathbf{b})$ reaction with $\mathrm{Na}_{2} \mathrm{CO}_{3}$. 
Table 2. EDS analysis of selected particles of hemimorphite in a and $b$.

\begin{tabular}{ccccc}
\hline \multirow{2}{*}{ Elment } & \multicolumn{2}{c}{ wt (\%) } & \multicolumn{2}{c}{ At (\%) } \\
\cline { 2 - 5 } & a (Before Adsorption) & $\mathbf{b}$ (After Adsorption) & a (Before Adsorption) & b (After Adsorption) \\
\hline CK & 00.60 & 03.61 & 02.02 & 14.11 \\
$O K$ & 19.06 & 08.10 & 47.87 & 23.74 \\
$S i K$ & 11.53 & 04.93 & 16.50 & 08.24 \\
$Z n K$ & 47.63 & 70.99 & 29.29 & 50.96 \\
$A u L$ & 21.18 & 12.37 & 04.32 & 02.95 \\
\hline
\end{tabular}

\subsection{XPS Measurements for the Transformation of $\mathrm{CO}_{3}{ }^{2-}$ on Hemimorphite}

The $\mathrm{C}$ element content on the surface of hemimorphite is still at a low level after acting with $\mathrm{Na}_{2} \mathrm{CO}_{3}$ analyzed by EDS. Thus, XPS was employed in this study for further explaining the existence of $\mathrm{CO}_{3}{ }^{2-}$ on hemimorphite surfaces treated with the $\mathrm{Na}_{2} \mathrm{CO}_{3}$ concentration of $1 \times 10^{-3} \mathrm{~mol} / \mathrm{L}$ because XPS is a useful tool for directly detecting the elemental compositions and chemical states of interaction products [36-38].

The C1s spectra of the treated and untreated hemimorphite sample with $\mathrm{Na}_{2} \mathrm{CO}_{3}$ are plotted in Figure 7. As shown in Figure 7a, the C1s peaks located at the binding energy values of $284.8 \mathrm{eV}$, $286.45 \mathrm{eV}$ and $289.05 \mathrm{eV}$ were attributed to the hydrocarbon and carbon-oxygen contaminants. The C1s peak in Figure $7 \mathrm{~b}$ has a certain change due to the instrument deviation, corresponding to the $284.8 \mathrm{eV}$, $286.28 \mathrm{eV}$ and $288.73 \mathrm{eV}$. As a result, the substantial contribution of C1s peaks to the transformed hemimorphite samples may be represented by the binding energy values of 289.59-289.26 eV [36,37], corresponding to the $289.75 \mathrm{eV}$ in Figure $7 \mathrm{~b}$, which is associated with the carbonate group. Some effects has occurred between $\mathrm{CO}_{3}{ }^{2-}$ and hemimorphite, while the intensity of carbonate group in $289.75 \mathrm{eV}$ is relatively low.

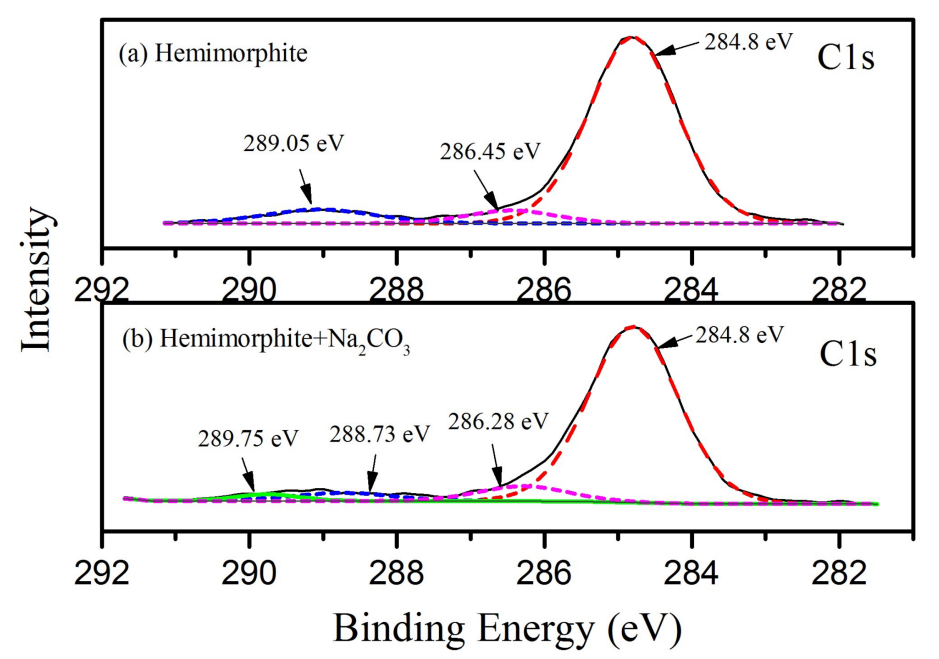

Figure 7. XPS Analysis for the treated and untreated hemimorphite with $\mathrm{Na}_{2} \mathrm{CO}_{3}$. (a) hemimorphite; (b) hemimorphite $+\mathrm{Na}_{2} \mathrm{CO}_{3}$.

\subsection{Analysis of Density of States of Hemimorphite after Interacting with $\mathrm{CO}_{3}{ }^{2-}$}

To further prove the possibility of the existence of the above mentioned smithsonite-like minerals, the relationship between $\mathrm{CO}_{3}{ }^{2-}$ and hemimorphite was calculated based on the first principles of DFT [39]. Figure 8 illustrates the transformation model before and after the reaction of hemimorphite. Calculations demonstrated carbon and oxygen atoms in $\mathrm{CO}_{3}{ }^{2-}$ tethered through a $\mathrm{C}-\mathrm{O}$ single bond, in which one oxygen (red part) interacted with $\mathrm{Zn}^{2+}$ (grey section) from the (100) plane of hemimorphite. 
The results of the analysis of density of states of $\mathrm{Zn}$ and $\mathrm{CO}_{3}{ }^{2-}$ are depicted in Figures 9 and 10 before and after the interaction.

(a)

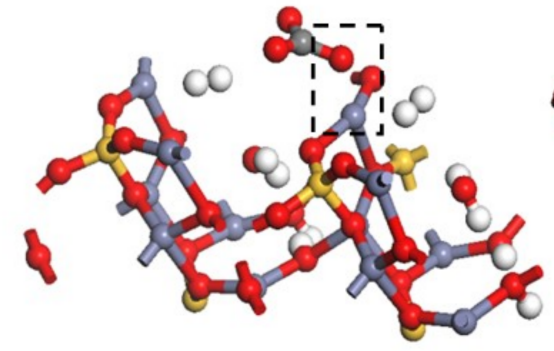

(b)

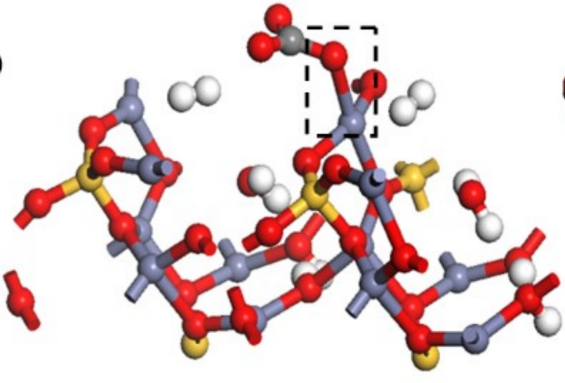

P

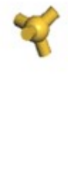
L.

Figure 8. Transformation of initial (a) and final (b) states of $\mathrm{CO}_{3}{ }^{2-}$ on the surface of the hemimorphite.

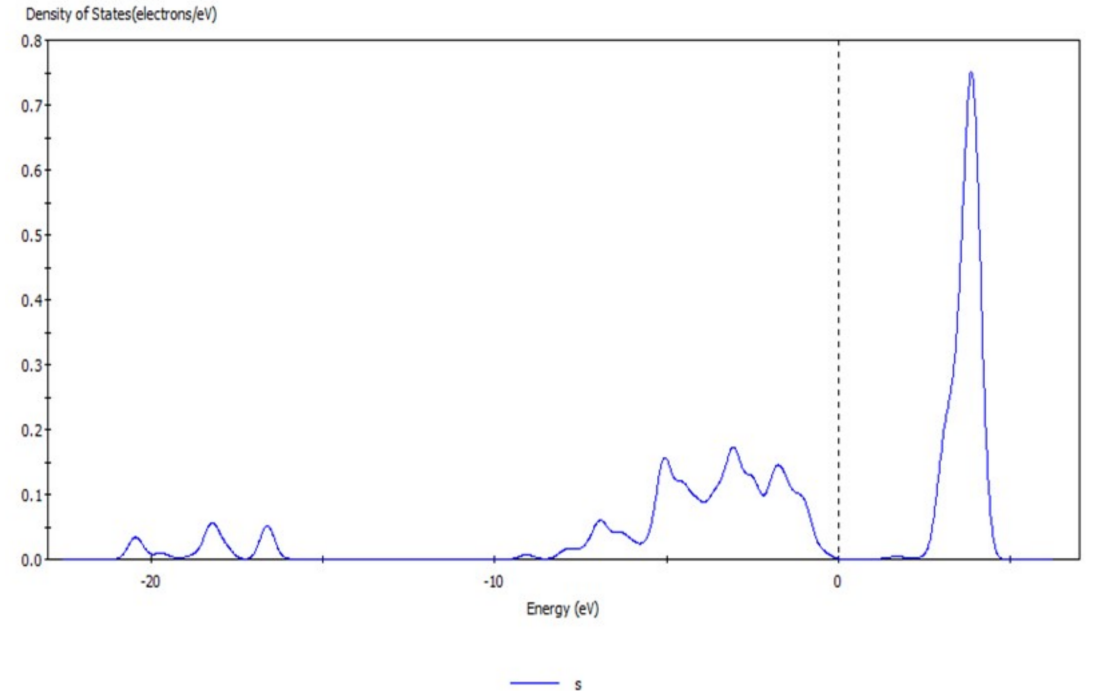

(a)

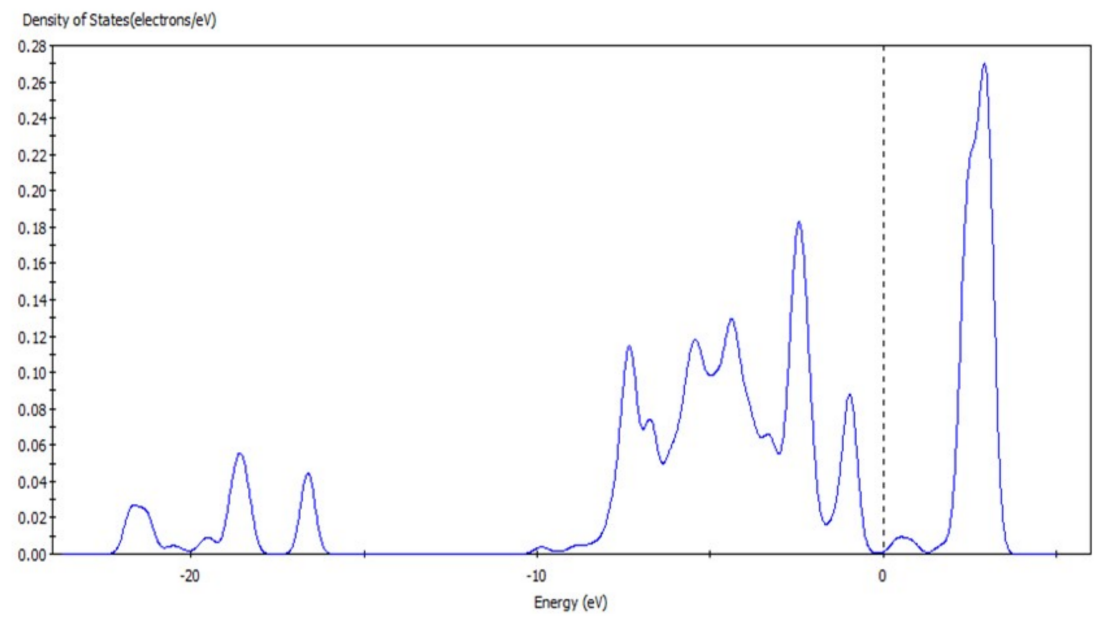

(b)

Figure 9. $\mathrm{s}$ orbital before (a) and after (b) transformation of $\mathrm{CO}_{3}{ }^{2-}$ with hemimorphite. 


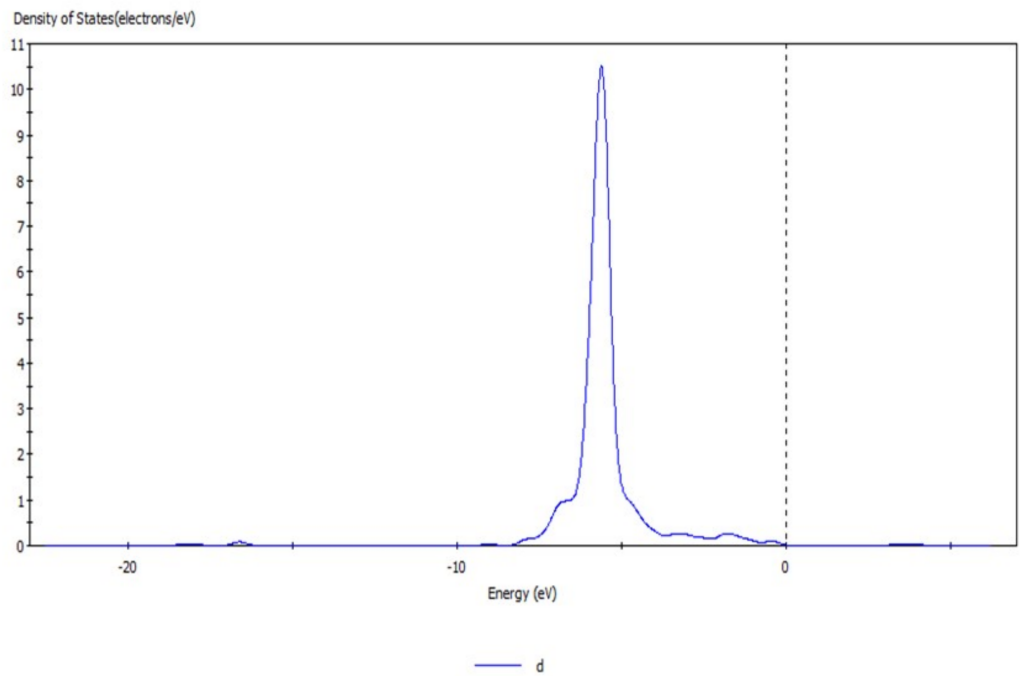

(a)

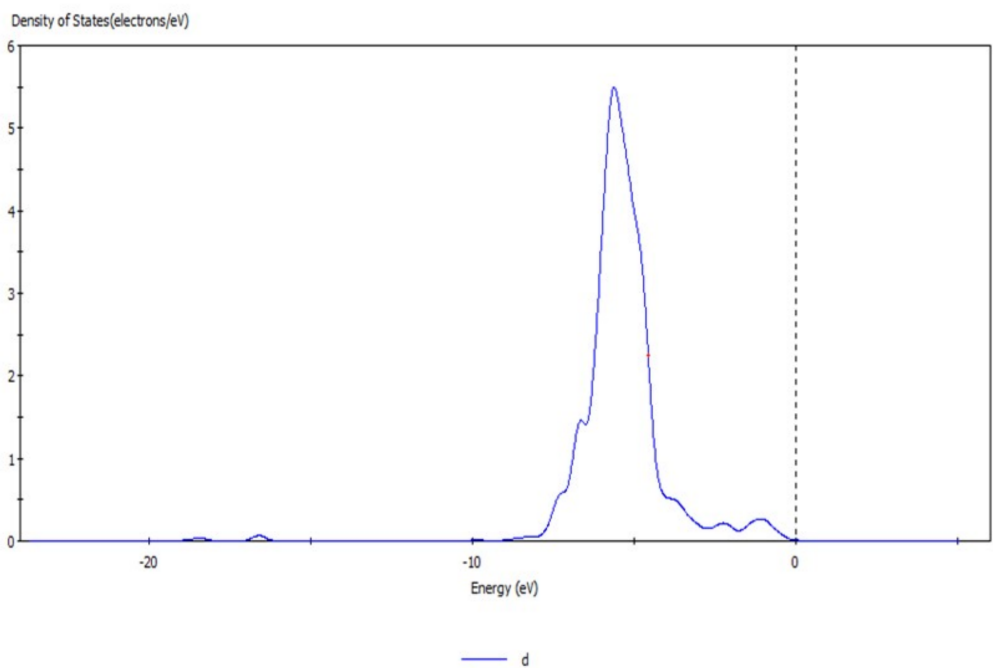

(b)

Figure 10. $\mathrm{d}$ orbital before (a) and after (b) transformation of $\mathrm{CO}_{3}{ }^{2-}$ with hemimorphite.

The peak values of the $\mathrm{s}$ and $\mathrm{d}$ orbitals of the $\mathrm{Zn}$ atom were reduced after reaction, and the density of states of the $\mathrm{d}$ orbital at $-5.63 \mathrm{eV}$ decreased obviously by $5.0 \mathrm{eV}$ by comparing the peak values of density of states before and after transformation with $\mathrm{CO}_{3}{ }^{2-}$. The $\mathrm{d}$ orbital of $\mathrm{Zn}$ atom lost electrons, and a new density of states arose at $-6.65 \mathrm{eV}$, which indicated that the electrons in the $\mathrm{d}$ orbital were involved in the bond-forming reactions. However, no significant change was observed in the localization of $\mathrm{s}$ and $\mathrm{d}$ orbitals and their peaks. Thus, the bond between $\mathrm{Zn}-\mathrm{O}$ was not strong, and $\mathrm{Zn}$ atoms on the surface were not completely substituted. Simultaneously, the reaction between $\mathrm{Zn}^{2+}$ and $\mathrm{CO}_{3}{ }^{2-}$ transformed smithsonite-like minerals $\left(\mathrm{ZnCO}_{3}\right)$; the surface of hemimorphite demonstrated similar properties to smithsonite-like minerals.

The bond length formed by the transformation of $\mathrm{CO}_{3}{ }^{2-}$ on hemimorphite was $2.159 \AA$ after calculation (see Figure 11). Compared with the Mulliken population of hemimorphite after reaction whose bond length of O 029-Zn 011 was $2.15893 \AA$ (Table 3, red box), both values were very close. The $\mathrm{Zn}-\mathrm{O}$ bond was formed by $\mathrm{CO}_{3}{ }^{2-}$ and $\mathrm{Zn}^{2+}$, whose Mulliken population value was 0.21 . We observed an overlap of electronic cloud between atoms, which demonstrated the bonding states. Its value was relatively small, and the covalent bond was weak compared with the other $\mathrm{O}-\mathrm{Zn}$ 
bond. Therefore, the property of the ionic bond was exhibited, which was consistent with the results of the analysis of density of states.

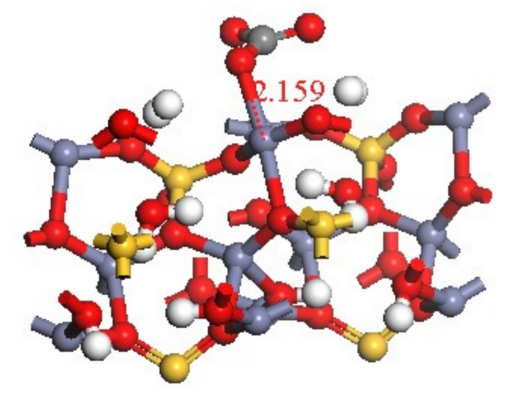

Figure 11. Bond length of $\mathrm{Zn}-\mathrm{O}$.

Table 3. Mulliken population value of partial bonds of hemimorphite after acting.

\begin{tabular}{cccc|}
\hline Bond & Population & Spin & Length $(\AA)$ \\
\hline O 024-Zn 006 & 0.22 & 0.00 & 2.11216 \\
O 005-Zn 006 & 0.18 & 0.00 & 2.12877 \\
\hline O 029-Zn 011 & 0.21 & 0.00 & 2.15893 \\
\hline O 016-Zn 009 & 0.11 & 0.00 & 2.16948 \\
O 014-Zn 007 & 0.14 & 0.00 & 2.17600 \\
\hline
\end{tabular}

\section{Conclusions}

The crystal of hemimorphite is a non-conductor because the density of states near the Fermi level is composed of $\mathrm{p}$ and d orbitals. Hemimorphite exhibits a large band gap between the valence band and conduction band. Poor abilities of electron transport and conductivity of hemimorphite were proven by unit cell modeling and band structure analysis. The Mulliken population value of the $\mathrm{Si}-\mathrm{O}$ bond was larger than that of the $\mathrm{Zn}-\mathrm{O}$ bond, indicating strong covalency. Therefore, the $\mathrm{Zn}-\mathrm{O}$ bond was mostly broken during rushing, and $\mathrm{Zn}-\mathrm{O}$ and $\mathrm{Zn}^{2+}$ were exposed on the mineral surface. The interaction between hemimorphite and polar water molecules was strong due to the strong ionicity and weak covalency of the $\mathrm{Zn}-\mathrm{O}$ bond, which demonstrated good hydrophilicity. This interaction was one of the reasons why hemimorphite was difficult to separate.

The EDS analysis showed that the carbon content on hemimorphite increased from $0.60 \%$ to $3.61 \%$, and XPS result revealed the carbonate group was detected at the binding energy values of $289.75 \mathrm{eV}$ after acting.

One oxygen in $\mathrm{CO}_{3}{ }^{2-}$ interacted with $\mathrm{Zn}^{2+}$ from the $\left(\begin{array}{lll}1 & 0 & 0\end{array}\right)$ plane of hemimorphite, as indicated by the transformation model and its new peak of density of states of the $\mathrm{d}$ orbital. The bonding reaction was observed through the analysis of density of states. The position of the $\mathrm{Zn}-\mathrm{O}$ bond should be in O 029-Zn 011, corresponding to the population of 0.21, which suggested the ionic bonds. Furthermore, the reaction between $\mathrm{CO}_{3}{ }^{2-}$ and $\mathrm{Zn}^{2+}$ was considered to transform a smithsonite-like mineral $\left(\mathrm{ZnCO}_{3}\right)$.

Acknowledgments: This study was financially supported by the National Natural Science Foundation of China (Nos. 20120034 and 51264019), National Basic Research Program of China (973 Program, Grant No. 2014CB643404), and the key Project of the National twelfth-five Year Research Program of China (Crant No. 2012BAB10B09) and the Analysis and Testing Foundation of Kunming University of Science and Technology (No. 201620070151).

Author Contributions: Xiaolin Zhang, Dianwen Liu conceived and designed the experiments; Shiming Cao and Qihong Wang performed the experiments; Xiaolin Zhang, Shiming Cao, Qihong Wang, Kaiwei Song, Man Jing, Kangkang Li, Luqing Wu and Ruizeng Liu analyzed the data; Qihong Wang wrote this paper and Dianwen Liu corrected it.

Conflicts of Interest: The authors declare no conflict of interest. 


\section{References}

1. Yan, L.G.; Wang, A.J.; Chen, Q.S.; Li, J.W. Dynamic material flow analysis of zinc resources in China. Resour. Conserv. Recycl. 2013, 75, 23-31. [CrossRef]

2. Zhang, X.F.; Hu, Y.H.; Sun, W.; Xu, L.H. The Effect of Polystyrene on the Carrier Flotation of Fine Smithsonite. Minerals 2017, 7, 52. [CrossRef]

3. Dai, S.F.; Chou, C.L.; Finkelman, R.B.; Seredin, V.V.; Zhou, Y.P. Geochemistry of trace elements in Chinese coals: A review of abundances, genetic types, impacts on human health, and industrial utilization. Int. J. Coal Geol. 2012, 94, 3-21. [CrossRef]

4. Dong, Y.H. Mineral Processing Research on a Complicated Refractory Zinc Oxide Ore. Hunan Nonferrous Met. 2015, 31, 23-26. (In Chinese)

5. Zhou, Q.; Yang, Y.Z.; Liang, Y.Q. Study on Mineral Processing Technology for Refractory Zinc Oxide Ore. Min. Metall. Eng. 2014, 34, 54-57. (In Chinese)

6. Pereira, C.A.; Peres, A.E.C. Reagents in calamine zinc ores flotation. Miner. Eng. 2005, 18, 275-277. [CrossRef]

7. Zhou, W. Study on Activation Behavior of $\alpha$-Nitroso- $\beta$-Naphthol in Flotation of Hemimorphite. Master's Thesis, Hunan University, Changsha, China, 2010; pp. 35-40. (In Chinese)

8. Chen, Y.; Chen, J.H.; Wu, B.Z.; Mu, X.; Wei, Z.W. Effect of synergism between hydroxy radical and sulfhydryl radical on the amine flotation of hemimorphite. Met. Mine 2009, 39, 65-68. (In Chinese)

9. Jia, K.; Feng, Q.M.; Zhang, G.F.; Shi, Q.; Chang, Z.Y. Understanding the roles of $\mathrm{Na}_{2} \mathrm{~S}$ and $\mathrm{Pb}$ (II)in the flotation of hemimorphite. Miner. Eng. 2017, 111, 167-173. [CrossRef]

10. Liu, C.; Feng, Q.M.; Zhang, G.F.; Ma, W.K.; Meng, Q.Y.; Chen, Y.F. Effects of lead ions on the flotation of hemimorphite using sodium oleate. Miner. Eng. 2016, 89, 163-167. [CrossRef]

11. Yuan, T.C.; Cao, Q.Y.; Li, J. Effects of mechanical activation on physicochemical properties and alkaline leaching of hemimorphite. Hydrometallurgy 2010, 104, 136-141.

12. Payne, M.C.; Teter, M.P.; Allan, D.C.; Arias, T.A.; Joannopoulos, J.D. Iterative minimization techniques for ab initio total-energy calculations: Molecular dynamics and conjugate gradients. Rev. Mod. Phys. 1992, 64, 1045-1097. [CrossRef]

13. Seryotkin, Y.V.; Bakakin, V.V. Structural evolution of hemimorphite at high pressure up to 4.2 Gpa. Phys. Chem. Miner. 2011, 38, 679-684. [CrossRef]

14. Validžić, I.L.; Mitrić, M.; Jokić, B.M.; Čomor, M.I. Structural and optical characterization of hemimorphite with flower-like morphology synthesized by a novel low-temperature method. Mater. Lett. 2012, 85, 138-141. [CrossRef]

15. Mao, M.; Li, Z.; Pan, Y. Phase transitions and proton ordering in hemimorphite: New insights from single-crystal EPR experiments and DFT calculations. Phys. Chem. Miner. 2012, 40, 133-143. [CrossRef]

16. Topsakal, M.; Cahangirov, S.; Bekaroglu, E.; Ciraci, S. A first-principles study of zinc oxide honeycomb structures. Phys. Rev. B 2009, 80, 235119. [CrossRef]

17. Guo, L.Q.; Wu, H.N.; Liu, J.H.; Ma, H.; Song, K.Y.; Li, D.Y. Density Functional theory study on energy band and density of states of ZnO. J. Synth. Cryst. 2009, 2, 440-444. (In Chinese)

18. Iokibe, K.; Sakamoto, T.; Tachikawa, H.; Azumi, K. Density functional theory study of zinc clusters. J. Surf. Finish. Soc. Jpn. 2009, 60, 592-597. [CrossRef]

19. Mohamad, A.A.; Hassan, M.S.; Yaakob, M.K.; Taib, M.F.M.; Badrudin, F.W.; Hassan, O.H.; Yahya, M.Z.A. First-principles calculation on electronic properties of zinc oxide by zinc-air system. J. King Saud Univ. Eng. Sci. 2017, 29, 278-283. [CrossRef]

20. Wu, D.D. Research on Ammonium Salton Strengthen Suifide Flotation Theory for Smithsonite. Ph.D. Thesis, Kunming University of Science and Technology, Kunming, China, 2015; pp. 60-69. (In Chinese)

21. Wu, L.; Hou, T.J.; Wang, Y.; Zhao, Y.F.; Guo, Z.Y.; Li, Y.Y.; Lee, S.T. First-principles study of doping effect on the phase transition of zinc oxide with transition metal doped. J. Alloys Compd. 2012, 541, 250-255. [CrossRef]

22. Shaik, S. A personal story on a renaissance in valence bond theory: A theory coming of age! Comput. Theor. Chem. 2017, 2, 1-30. [CrossRef]

23. Andrés, R.B.M.; Florentino, L.U.; Mauricio, T.; Humberto, T. Effect of impurities on the electronic and magnetic properties of zinc oxide nanostructures. Chem. Phys. Lett. 2010, 492, 82-88.

24. Magnasco, V. Chapter 15: Valence bond theory and the chemical bond. In Elementary Methods of Molecular Quantum Mechanics; Elsevier: Amsterdam, The Netherlands, 2013; pp. 599-680. 
25. Hu, Z.Q. Molecular orbital theory studies on bond energy I. theoretic equation. Acta Chim. Sin. 1998, 56, 353-358. (In Chinese)

26. Ikeda, A.; Nakao, Y.; Sato, H.; Sakaki, S. A resonance theory consistent with Mulliken-population concept. Chem. Phys. Lett. 2011, 505, 148-153. [CrossRef]

27. Ogorodnikova, N.A. On invariance of the Mulliken substituent-induced charge changes in quantum-chemical calculations of different levels. J. Mol. Struct. THEOCHEM 2009, 894, 41-49. [CrossRef]

28. Magnasco, V. Chapter 10: Valence bond theory and the chemical bond. In Elementary Methods of Molecular Quantum Mechanics; Elsevier: Amsterdam, The Netherlands, 2007; pp. 473-575.

29. Pipek, J. Unique positive definite extension of Mulliken's charge populations of non-orthogonal atomic basis functions. J. Mol. Struct. THEOCHEM 2000, 501-502, 395-401. [CrossRef]

30. Kaupp, M.; Danovich, D.; Shaik, S. Chemistry is about energy and its changes: A critique of bond-length/bond-strength correlations. Coord. Chem. Rev. 2017, 344, 355-362. [CrossRef]

31. Gunnarsson, O.; Jones, R.O. Self-interaction corrections in the density functional formalism. Solid State Commun. 1981, 37, 249-252. [CrossRef]

32. Gao, Z.Y.; Sun, W.; Hu, Y.H. Mineral cleavage nature and surface energy: Anisotropic surface broken bonds consideration. Trans. Nonferrous Met. Soc. China 2014, 24, 2930-2937. [CrossRef]

33. Ren, S.P.; Tong, X.; Zhou, Y.C. Study and application of desilication process in mineral processing. Min. Metall. 2013, 22, 32-36. (In Chinese)

34. Ejtemaei, M.; Gharabaghi, M.; Irannajad, M. A review of zinc oxide mineral beneficiation using flotation method. Adv. Colloid Interface Sci. 2014, 206, 68-78. [CrossRef] [PubMed]

35. Wang, Q.H.; Zhang, X.L.; Jing, M.; Rao, F.; Wu, L.Q.; Li, K.K.; Cao, S.M. A review of forming process and flotation mechanism of hemimorphite. Chin. J. Process Eng. 2017, 17, 903-910. (In Chinese)

36. Feng, Q.C.; Zhao, W.J.; Wen, S.M.; Cao, Q.B. Activation mechanism of lead ions in cassiterite flotation with salicylhydroxamic acid as collector. Sep. Purif. Technol. 2017, 178, 193-199. [CrossRef]

37. Feng, Q.C.; Wen, S.M.; Deng, J.S.; Zhao, W.J. Combined DFT and XPS investigation of enhanced adsorption of sulfide species onto cerussite by surface modification with chloride. Appl. Surf. Sci. 2017, 425, 8-15. [CrossRef]

38. Feng, Q.C.; Zhao, W.J.; Wen, S.M. Surface modification of malachite with ethanediamine and its effect on sulfidization flotation. Appl. Surf. Sci. 2018, 436, 823-831. [CrossRef]

39. Yadav, S.K.; Sadowski, T.; Ramprasad, R. Density functional theory study of $\mathrm{ZnX}(X=\mathrm{O}, \mathrm{S}, \mathrm{Se}, \mathrm{Te})$, under uniaxial strain. Phys. Rev. B 2010, 81, 144120. [CrossRef] 